\title{
Intra-Axonal Translation of RhoA Promotes Axon Growth Inhibition by CSPG
}

\author{
Breset A. Walker, ${ }^{\star}$ Sheng-Jian Ji, ${ }^{\star}$ and Samie R. Jaffrey \\ Department of Pharmacology, Weill Medical College, Cornell University, New York, New York 10065
}

Chondroitin sulfate proteoglycans (CSPGs) are a major component of the glial scar that contributes to the limited regeneration of the CNS after axonal injury. However, the intracellular mechanisms that mediate the effects of CSPGs are not fully understood. Here we show that axonal growth inhibition mediated by CSPGs requires intra-axonal protein synthesis. Application of CSPGs to postnatal rat dorsal root ganglia axons results in an increase in the axonal levels of phosphorylated 4E-BP1, a marker of increased protein translation. Axons grown in media containing CSPGs exhibit markedly reduced growth rates, which can be restored by the selective application of protein synthesis inhibitors to distal axons. We show that these axons contain transcripts encoding RhoA, a regulator of the cytoskeleton that is commonly used by the signaling pathways activated by many inhibitors of axon growth. We also show that selective application of CSPGs to axons results in increased intra-axonal synthesis of RhoA and that depletion of RhoA transcripts from axons results in enhanced growth of axons in the presence of CSPGs. These data identify local translation as an effector pathway of CSPGs and demonstrate that local translation of RhoA contributes to the axon growth inhibitory effect of CSPGs.

\section{Introduction}

The chondroitin sulfate proteoglycans (CSPG) family of extracellular matrix molecules has roles in cell division, tissue morphogenesis, and axon growth signaling pathways (Wight et al., 1992). CSPGs are upregulated in astrocyte and oligodendrocyte progenitors after axonal injury in the CNS, resulting in a chemorepellent barrier to axonal growth (Silver and Miller, 2004).

CSPGs and other axonal growth inhibitors that interfere with axon regeneration activate the monomeric GTPase RhoA (Niederöst et al., 2002; Fournier et al., 2003). When activated, RhoA promotes F-actin disassembly in axonal growth cones (Maekawa et al., 1999), preventing the recruitment of microtubules needed for axon regeneration (Rodriguez et al., 2003). Both total RhoA and active RhoA levels increase after axonal injury (Dubreuil et al., 2003; Conrad et al., 2005). RhoA activity is induced by CSPGs (Monnier et al., 2003; Jain et al., 2004; Fu et al., 2007), as well as by myelin-derived inhibitors, such as myelin-associated glycoprotein (MAG) and Nogo (Niederöst et al., 2002). Inhibition of either RhoA or Rho-associated kinase (ROCK), a major RhoA effector, leads to improved axon regeneration and functional recovery after axonal injury in mice, underscoring the central role of RhoA in mediating the effects of axon growth inhibitors. Although RhoA is a central regulator of axonal growth, the molec-

Received Jan. 12, 2012; revised Aug. 20, 2012; accepted Aug. 24, 2012.

Author contributions: B.A.W., S.-J.J., and S.R.J. designed research;B.A.W. and S.-J.J. performed research; B.A.W., S.-J.J., and S.R.J. analyzed data; B.A.W., S.-J.J., and S.R.J. wrote the paper.

This work was supported by the Christopher Reeve Paralysis Foundation, the New York State Spinal Cord Injury Research Trust Fund DOH Contract C023832 and NIH Grants NINDS NS56306 (S.R.J.) and T32DA007274 (B.A.W). We thank A. Deglincerti for helpful suggestions.

*B.A.W. and S.-J.J. contributed equally to this work.

Correspondence should be addressed to Samie R. Jaffrey, Department of Pharmacology, Weill Medical College, Cornell University, 1300 York Avenue, Box 70, New York, NY 10065. E-mail: srj2003@med.cornell.edu.

DOI:10.1523/JNEUROSCI.0176-12.2012

Copyright $\odot 2012$ the authors $\quad 0270-6474 / 12 / 3214442-06 \$ 15.00 / 0$ ular mechanisms that lead to increases in RhoA activity in response to inhibitory signals are not fully understood. Thus, identifying mechanisms that lead to RhoA activation in injured axons is important for developing therapeutic strategies to promote axon growth.

A mechanism to selectively control the spatial expression of proteins in neurons is local translation. During embryonic development, growing axons contain readily detectable ribosomes and mRNA (Zivraj et al., 2010). Axonal transcripts encoding cytoskeleton components and regulators such as $\beta$-actin, RhoA, and PAR3 have been found in axons (Piper and Holt, 2004; Wu et al., 2005; Hengst et al., 2009). RhoA transcripts have been detected in axons of embryonic dorsal root ganglia (DRG), retinal ganglion, and cortical and hippocampal neurons, and are locally translated in DRG axons in response to the inhibitory guidance cue Semaphorin $3 \mathrm{~A}$ (Sema3A) and mediate growth cone collapse (Wu et al., 2005). Regenerating axons also contain ribosomes and locally translate proteins (Zheng et al., 2001; Verma et al., 2005). Thus, local translation might mediate responses to axon growth inhibitory molecules. However, no signaling pathways that are relevant to regenerating axons have been shown to induce the translation of specific proteins. Here we examine the role of local translation in mediating the effects of CSPGs on axon outgrowth. We find that RhoA transcripts are localized to axons, translated in response to CSPGs, and promote the axon growth-inhibitory effects of CSPG.

\section{Materials and Methods}

Microfluidic culture and selective treatments of axons. Unless otherwise indicated, reagents were obtained from Invitrogen. Neurons were cultured on glass coverslips (Carolina Biological Supply) or plastic (BD Bioscience) coated with $0.01 \%$ poly-L-lysine and $0.3 \mathrm{mg} / \mathrm{ml}$ laminin (both from Trevigen). CSPG was coated on glass following a standard protocol (Dergham et al., 2002). DRG neurons were harvested from 
postnatal day 4-6 (P4-P6) rats of either sex as described previously (Walker et al., 2012). To remove attached glia, ganglia were treated twice with $0.1 \%$ collagenase (Wellington) followed by TrypLE. The neurons were purified on a $32 \% / 54 \%$ Percoll gradient. Approximately 15,000 neurons per microfluidic chamber were cultured in Neurobasal supplemented with B27, 2 mM glutamine, $100 \mathrm{IU}$ penicillin, and $100 \mu \mathrm{g} / \mathrm{ml}$ streptomycin. Axonal identity of crossed processed was confirmed with GAP43 immunohistochemistry.

Axon-specific RhoA knock down. Neurons were cultured for $36 \mathrm{~h}$ in microfluidic chambers to allow axons to enter the axonal compartment. Then, FITC-labeled, RhoA-specific siRNAs (GAGCCUUUGCAUCUAAGAA; ACAUGCUUGCUCAUAGUCUU) or the Allstars Negative Control (Qiagen) were transfected in distal axons using GeneSilencer (Genlantis) transfection reagent as described previously (Hengst et al., 2006), and the cells were cultured for $36 \mathrm{~h}$ before imaging. To confirm that axon-specific knockdown does not affect mRNA in cell bodies, only cell bodies in which a contiguous axon from the axonal compartment could be detected were examined.

Measurement of axonal growth rates. Thirty minutes before imaging on day in vitro (DIV) 3, $1 \mu \mathrm{M}$ cycloheximide (Sigma-Aldrich), $50 \mu \mathrm{M}$ Y-27632 (Tocris Bioscience), or vehicle was added to the axonal compartment. After capturing phase contrast images $(20 \times), 20 \mu \mathrm{g} / \mathrm{ml}$ MAG-Fc (R\&D Systems), $2 \mu \mathrm{g} / \mathrm{ml}$ CSPGs (Chicken CSPG; Millipore; this concentration was determined by a dose-response assay), $4 \mu \mathrm{M}$ Nogo-66 (Alpha Diagnostics), or vehicle were added to the axonal compartment using established protocols (Shen et al., 2009; Kurihara and Yamashita, 2012). After $3 \mathrm{~h}$, images of the same axons were taken. Only axons without varicosities or blebbing, and that did not contact other axons, were evaluated. Axon length was measured using NIS-Elements (Nikon). Experimental groups were uncoded after imaging and data analysis.

In situ hybridization and immunocytochemistry. Fluorescent in situ hybridization (FISH) was performed using digoxigenin-labeled riboprobes as described previously (Cox et al., 2008). Antibodies for immunohistochemistry were anti-digoxin (1:500; DI-22; Sigma), anti-GAP43 (1:2000; Millipore), RhoA (1:1000; Santa Cruz Biotechnology), p4E-BP1 Ser65/ Thr70 (1:200; Santa Cruz Biotechnology), and 4E-BP1 (1:250; Cell Signaling Technology).

Image acquisition and fluorescence quantification. Images and measurements were of the terminal $50 \mu \mathrm{m}$ of the axon $(60 \times)$. Exposure times were determined empirically for each riboprobe and antibody, and kept constant below gray scale saturation. Image stacks were deconvoluted using AutoDeblur X2 (AutoQuant). To normalize RhoA and digoxigenin immunofluorescence intensity, the GAP43 signal was thresholded to create a volume mask, and the RhoA or digoxigenin signal intensity was measured within this volume. Image analysis was performed with NIS-Elements. Sample identities were revealed after imaging and data analysis.

Statistical analysis. Statistical analysis was performed with GraphPad Prism 5. Three or more groups were compared with one-way ANOVA with Bonferroni posttest. Two groups were compared with an unpaired, two-tailed, Student's $t$ test, with Welch's correction if applicable. Alpha levels were set to $5 \%$. In all figures, error bars represent mean \pm SEM from at least three independent replicates.

\section{Results}

CSPG-dependent axon growth inhibition requires local protein synthesis

Typically, CSPGs are bath-applied to neurons or included in the substratum on which the neurons are plated (Dergham et al., 2002; Shen et al., 2009). These methods are problematic since they can cause activation of CSPG signaling pathways in cell bodies as well as axons. Under physiological conditions, however, CSPGs are synthesized at sites of injury, and therefore only axons are exposed to CSPGs. Thus, to mimic physiologic CSPG signaling, which occurs in distal axons, we used a microfluidic approach to selectively apply CSPGs to axons. P6 rat DRG neurons were cultured in a polydimethylsiloxane-based microfluidic
A

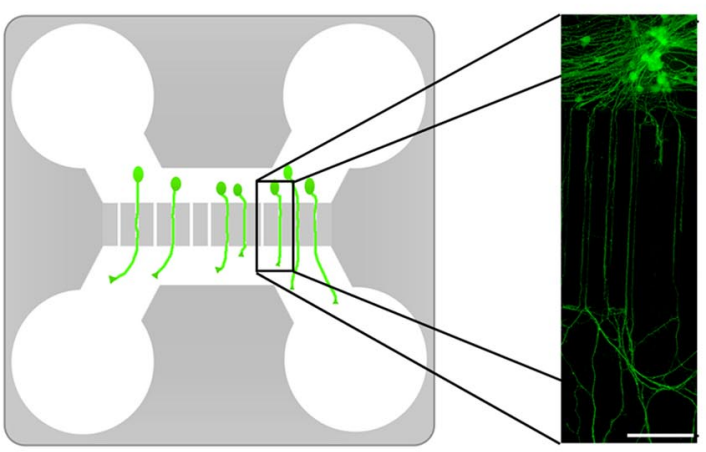

B
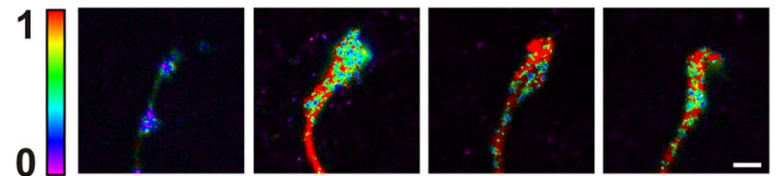

Vehicle

MAG

CSPG

Nogo

C

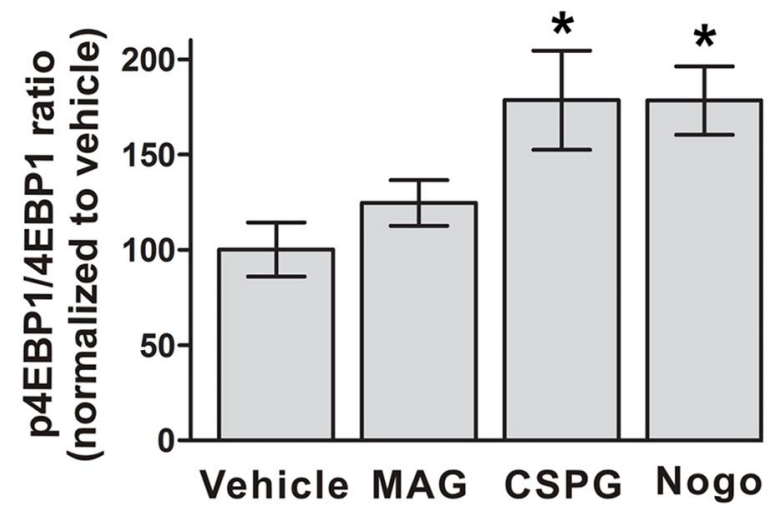

Figure 1. CSPGs induce markers of intra-axonal protein translation. $\boldsymbol{A}$, Diagram of microfluidic chamber. The chamber consists of cell body and axonal compartments connected by microgrooves. Right, Anti-GAP43 (green) immunofluorescence image of rat DRG neurons with axons extending through the microgrooves. Scale bar, $100 \mu \mathrm{m}$. $\boldsymbol{B}$, Heat map of the ratio of $\mathrm{p} 4 \mathrm{E}-\mathrm{BP} 1$ to total $4 \mathrm{E}-\mathrm{BP} 1$ shows increased translational activity in axons after exposure to MAG-Fc, CSPG, or Nogo-66. Exposure to these growth inhibitory proteins alters growth cone morphology. Scale bar, $5 \mathrm{~nm}$. $\boldsymbol{C}$, Quantification of data shown in $\boldsymbol{B}$. Treatment of axons with CSPGs or Nogo-66, but not MAG-Fc, for 5 min increased the ratio of $\mathrm{p} 4 \mathrm{E}-\mathrm{BP} 1$ to total $4 \mathrm{E}-\mathrm{BP} 1$ relative to vehicle. ${ }^{*} p<0.05$, compared with vehicle, ANOVA with Bonferroni posttest. Data are mean \pm SEM.

chamber, which consists of a cell body compartment and a distal axon compartment separated by embedded microgrooves $(10 \times$ $150 \mu \mathrm{m}$ ) that allow spatial and fluidic isolation of axons from cell bodies (Taylor et al., 2005). The chambers were assembled so that the media in the axonal compartment contained CSPGs, myelinassociated inhibitors, or vehicle. Thus, axons only encountered growth inhibitors once they exited the microgrooves and entered the axonal compartment.

We first examined whether CSPGs induce protein synthesis in axons. Multisite phosphorylation of 4E-BP1 on Ser64 and Thr69 is required for mRNA translation (Richter and Sonenberg, 2005). For these studies, we used P6 DRG neurons, which are axotomized when harvested from pups. Cultured early postnatal DRG neurons exhibit sensitivity to CSPGs and myelin-associated inhibitors of axon growth (Niederöst et al., 2002; Shen et al., 2009; Ma et al., 2010). P6 DRG neurons were cultured in microfluidic chambers (Fig. 1A), and on DIV3 axons were treated with vehicle, $20 \mu \mathrm{g} / \mathrm{ml}$ MAG-Fc, $4 \mu \mathrm{M}$ Nogo, or $2 \mu \mathrm{g} / \mathrm{ml}$ CSPGs for 


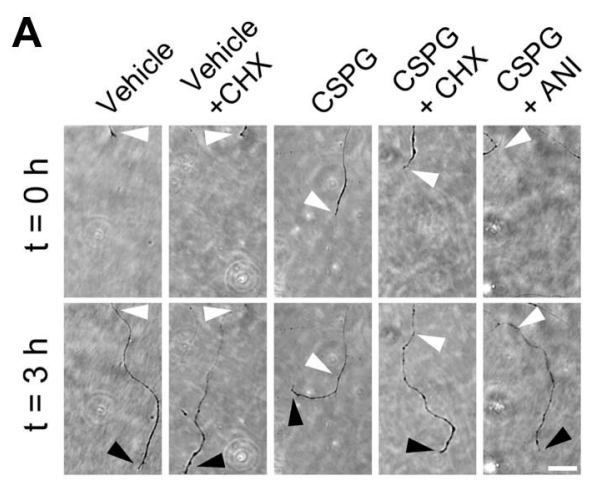

\section{B}

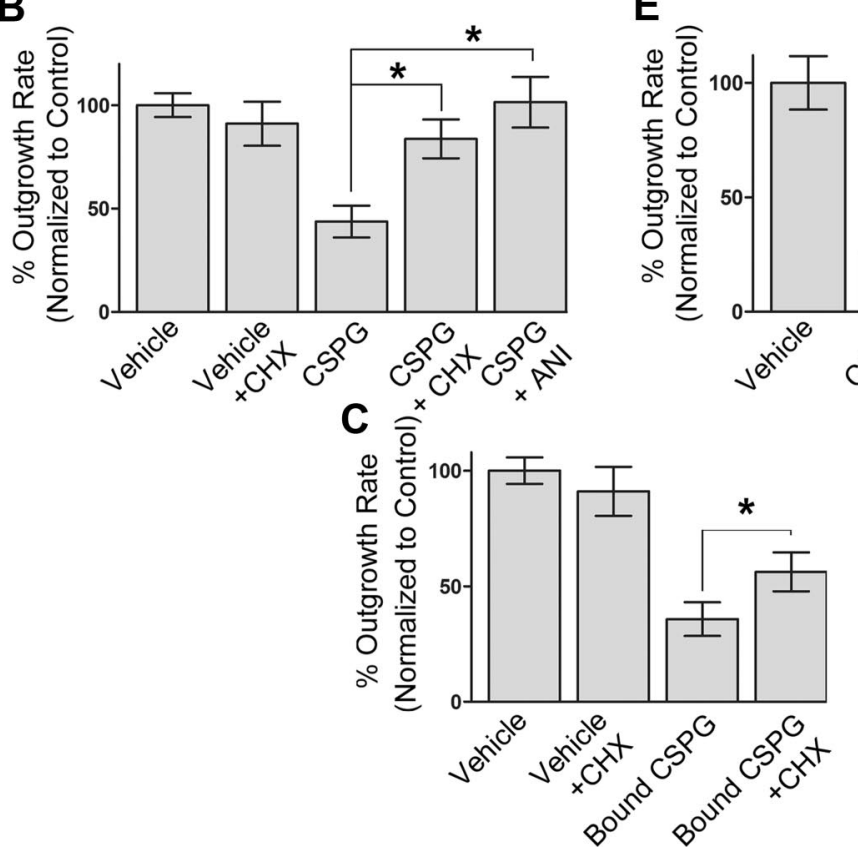

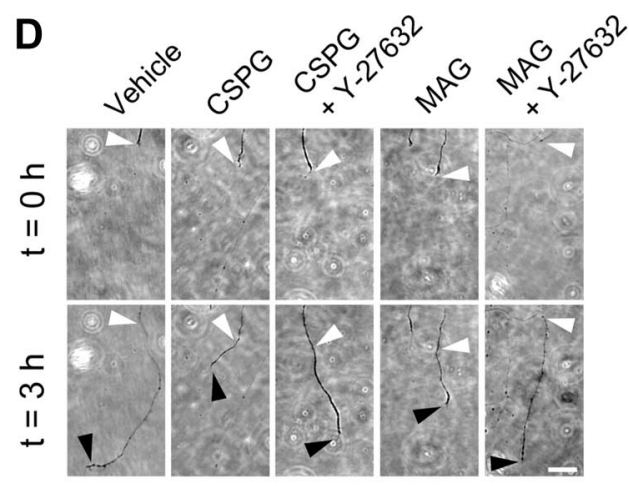

E

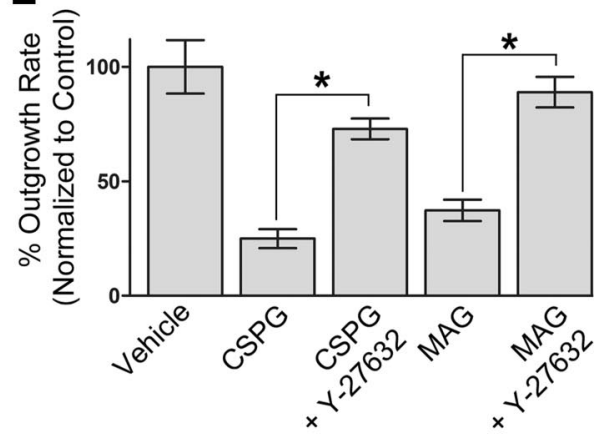

Figure 2. Local translation and RhoA activity are required for the axon growth-inhibiting effects of CSPGs. A, Axonal application of cycloheximide (CHX) or anisomycin (ANI) blocks CSPG-mediated inhibition of axon growth. Shown are phase contrast images of axons at $t=0 \mathrm{~h}$ (terminals are indicated by white arrowheads) and $t=3 \mathrm{~h}$ (terminals are indicated by black arrowheads). Scale bar, $50 \mu \mathrm{m}$. $\boldsymbol{B}$, Quantification of the results in $\boldsymbol{A}$. Axons grow significantly slower in media containing (SPG than vehicle. Coapplication of cycloheximide or anisomycin with CSPG blocked CSPG-mediated growth inhibition. C, Selective application of cycloheximide blocks the inhibition of axon growth by substrate-bound CSPG. This effect is similar to bath application of CSPG in $\boldsymbol{A}$ and $\boldsymbol{B}$. D. Axon-specific inhibition of ROCK prevents the inhibition of axon growth rate by CSPGs or MAG-Fc. Shown are phase contrast images of axon terminals at $t=0 \mathrm{~h}$ (white arrowheads) and $t=3 \mathrm{~h}$ (black arrowheads). Scale bar, $50 \mu \mathrm{m}$. $\boldsymbol{E}$, Quantification of the results in $\boldsymbol{D}$. Axons grow significantly slower in media containing either CSPG or MAG-Fc versus vehicle. Coapplication of Y-27632, but not vehicle, blocked CSPG- and MAG-mediated axon growth inhibition. ${ }^{*} p<0.05$, compared with control group as indicated $(\boldsymbol{B}, \boldsymbol{C}$, and $\boldsymbol{E})$, ANOVA with Bonferroni posttest. Data are mean \pm SEM.

5 min. CSPGs and Nogo treatment resulted in increased levels of phosphorylated 4E-BP1 relative to total 4E-BP1 levels, indicating that CSPGs may induce local protein synthesis (Fig. $1 B, C)$.

To determine whether local protein synthesis mediates CSPGdependent axon growth inhibition, we monitored the effects of protein synthesis inhibitors on axonal growth. The ability of protein synthesis inhibitors to block protein translation in microfluidic chambers has been previously demonstrated (Cohen et al., 2011). Axon growth was not substantially affected by application of protein synthesis inhibitors to axons (Fig. $2 A, B$ ), consistent with previous studies showing that inhibition of local translation does not affect basal axon growth rates (Eng et al., 1999; Zheng et al., 2001; Hengst et al., 2009). Axons growing in media containing CSPGs exhibited a $55 \pm 9 \%$ reduction in axon growth rates compared with axons exposed to vehicle, consistent with previous data showing that CSPGs inhibit the growth of neurites (Dou and Levine, 1994). However, selective application of cycloheximide or anisomycin to axons treated with CSPGs significantly $(p<$ 0.05 ) reduced CSPG-dependent axon growth inhibition (Fig. $2 A, B)$. Similar effects were found when CSPG was applied in the substratum of the axonal compartment in the microfluidic chamber (Fig. 2C). Together, these data indicate that intraaxonal protein synthesis is necessary for the CSPG-induced reduction in axon growth rate.

\section{RhoA transcripts are localized to axons and translated in response to CSPGs}

Because CSPG-mediated axonal growth inhibition is RhoAdependent (Monnier et al., 2003; Jain et al., 2004; Fu et al., 2007), we considered the possibility that RhoA activity in the distal axon is required for the effects of axonal growth inhibitors. Application of CSPGs or MAG to the axonal compartment resulted in decreased axon growth, consistent with previous studies of neurons cultured on CSPGs or myelin-containing substrates (Dergham et al., 2002). Selective coapplication of Y-27632, an inhibitor of 

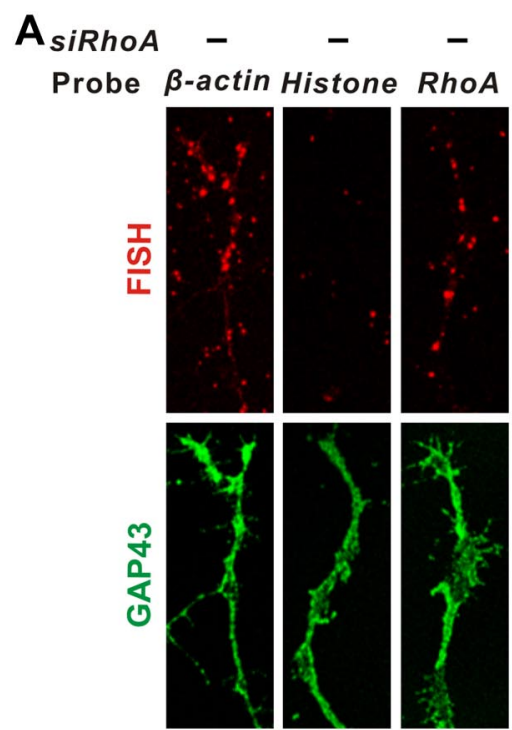

B
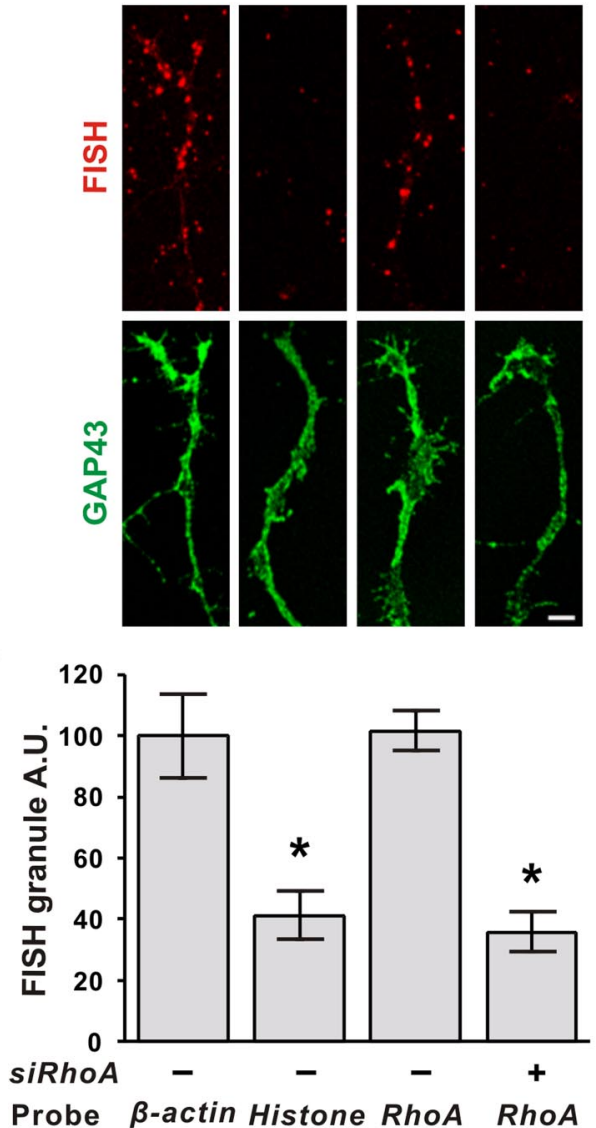
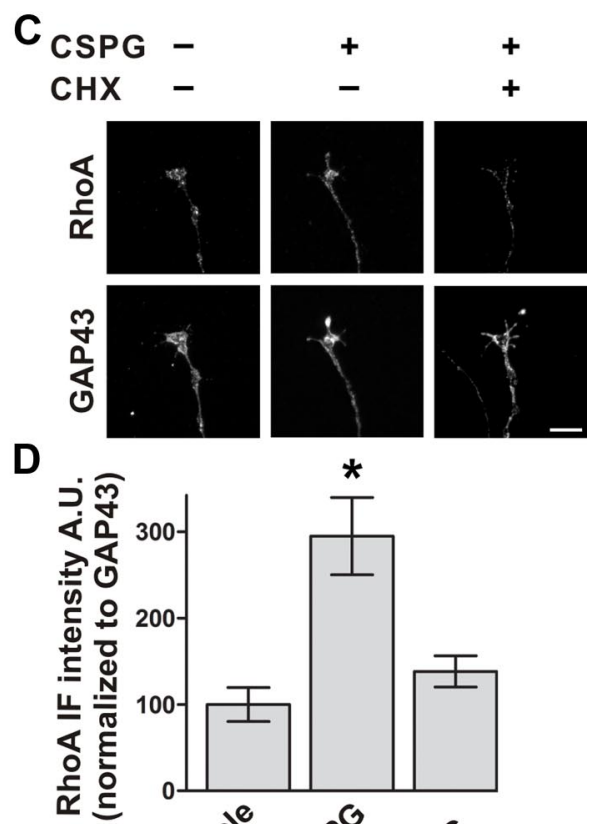

$\mathbf{E}$

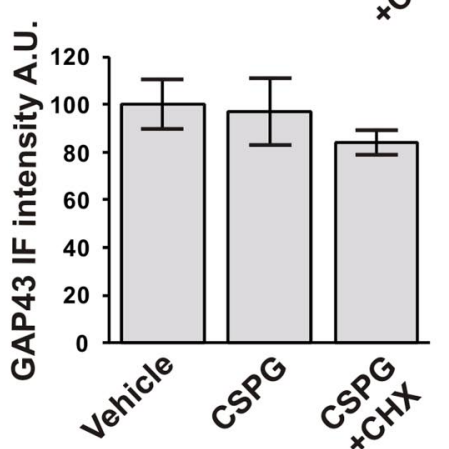

Figure 3. CSPG induces local translation of RhoA. A, Detection of RhoA transcript in axons by FISH. RhoA and $\beta$-actin transcripts were detected in axons in a characteristic punctate pattern (red). Histone-specific probes exhibited minimal reactivity, similar to RhoA probes in RhoA-specific siRNA (siRhoA)-treated axons. GAP43 immunostaining (green) was used to visualize axonal borders. Scale bar, $5 \mu \mathrm{m}$. B, Quantification of FISH signals in $\boldsymbol{A}$. C, Axonal expression of RhoA after exposure to CSPGs. Application of CSPG to the axonal compartment increased the amount of RhoA in axons as measured with anti-RhoA immunofluorescence. This effect was blocked by cycloheximide (CHX). Scale bar, $5 \mu \mathrm{m}$. $\boldsymbol{D}$, Quantification of RhoA in $\boldsymbol{C}$. $\boldsymbol{E}, \mathrm{GAP} 43$ protein levels were not changed by CSPG or cycloheximide treatment used in $\boldsymbol{C}$ and $\boldsymbol{D}$. ${ }^{*} p<0.05$, compared with $\beta$-acin group $(\boldsymbol{B})$ or vehicle group $(\boldsymbol{D}, \boldsymbol{E})$, ANOVA with Bonferroni posttest. Data are mean \pm SEM. A.U., Arbitrary units.

ROCK, with CSPG to the axonal compartment resulted in axonal growth rates that were $75-90 \%$ of control rates (Fig. 2D,E). These data indicate that intra-axonal RhoA signaling contributes to the reduced growth rates seen in axons growing on CSPGs.

Because RhoA transcripts have previously been localized to axons of different embryonic neuronal subtypes (Wu et al., 2005; Zivraj et al., 2010), we considered the possibility that axonally localized RhoA mRNA could contribute to the effects of CSPGs. To test this idea, we first examined whether RhoA mRNA is localized to axons of P6 DRG neurons. FISH using RhoA-specific riboprobes revealed significant levels of RhoA mRNA in the axons of DIV3 P6 DRG neurons, but not in RhoA-specific siRNA-treated axons (Fig. $3 A, B$ ). The RhoA signal was granular and localized throughout the growth cone, as seen with other axon-enriched transcripts (Zivraj et al., 2010). The intensity of the labeling for the RhoA transcript in axons was similar to that for $\beta$-actin mRNA, another axonally localized transcript (Fig. $3 A, B$ ).

We next asked whether RhoA is locally synthesized in response to CSPGs. Selective application of CSPGs to P6 DRG ax- ons grown in microfluidic chambers resulted in a $136 \pm 33 \%$ increase in RhoA protein levels compared with vehicle treatment (Fig. 3C-E). To determine whether this effect was due to intraaxonal protein synthesis, we selectively applied cycloheximide to the axonal compartment along with CSPGs. Under these conditions, the increase in RhoA protein levels was blocked (Fig. 3C$E)$, indicating that CSPG-induced increases in RhoA levels are due intra-axonal protein synthesis.

Axon-selective knockdown of RhoA impairs CSPG-dependent growth inhibition

We next asked whether CSPG-induced increases in RhoA levels contribute to its axon growth-inhibitory effects. To test this, we used axon-selective mRNA knockdown. With this technique, siRNAs are transfected only into axons to achieve knockdown of target mRNAs in axons, without affecting mRNA levels in cell bodies (Hengst et al., 2006). P6 DRG neurons were cultured in microfluidic chambers for $36 \mathrm{~h}$, and axons were transfected with either one of two RhoA-specific siRNAs. Axonal transfection with either RhoA-specific siRNA, 
A

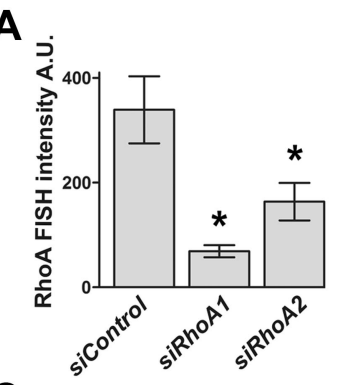

B

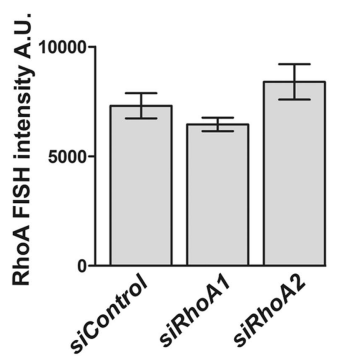

C
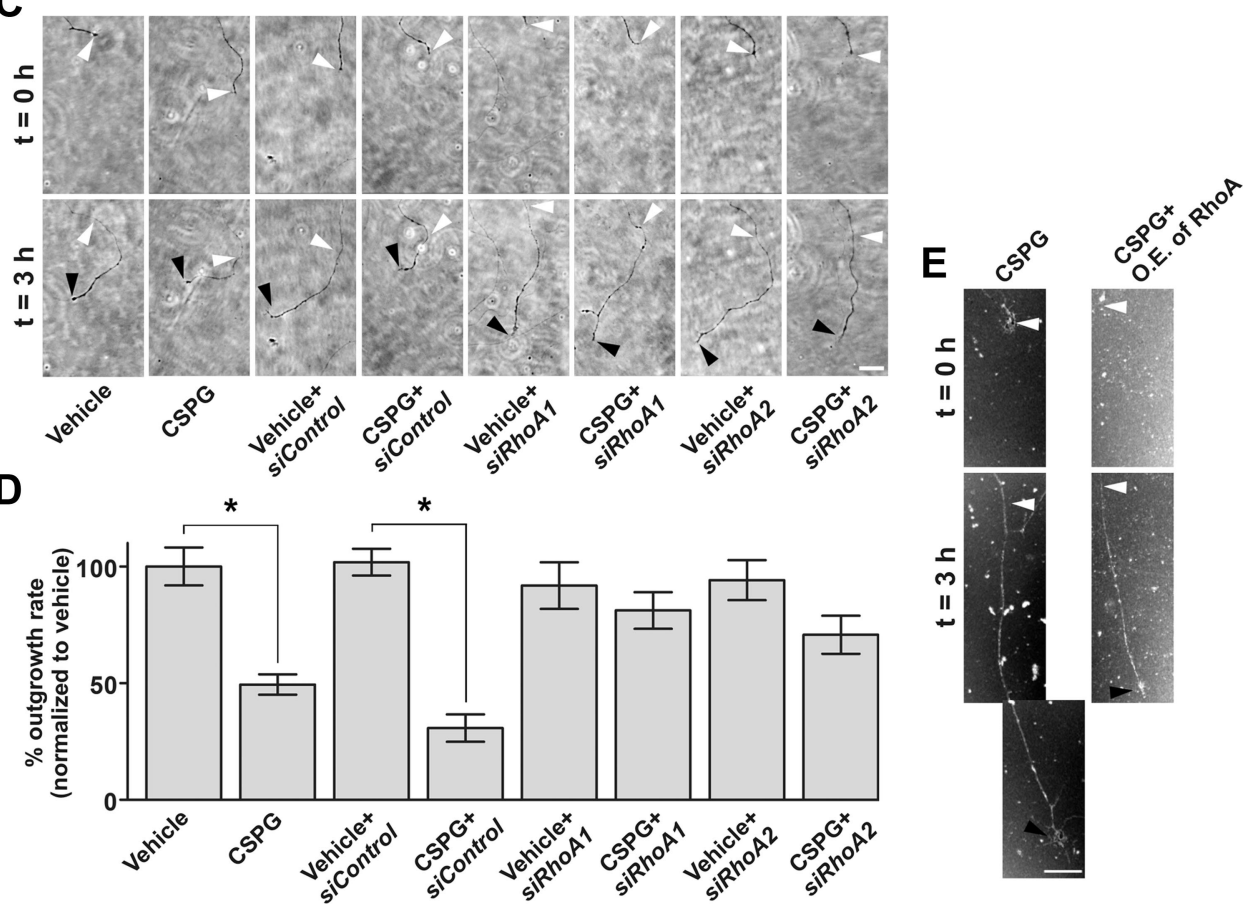

Figure 4. Local translation of RhoA is required for CSPG-mediated axon outgrowth inhibition. $A, B$, Axon-specific knockdown of RhoA transcripts. siRNA were applied to the axonal compartment and $R h o A$ mRNA levels were measured by FISH after $36 \mathrm{~h}$. Transfection of either of two RhoA-specific siRNAs (siRhoA1 and siRhoA2) resulted in knockdown of axonal RhoA transcript levels (A) compared with control siRNA (siControl). Cell body RhoA transcripts are not affected by axon-specific siRNA transfection as demonstrated by FISH (B). C, D, Axon-specific knockdown of RhoA blocked CSPG-mediated inhibition of axonal growth. Phase contrast images of axons at $t=0 \mathrm{~h}$ (terminals indicated by white arrowheads) and $t=3 \mathrm{~h}$ (terminals indicated by black arrowheads) are shown in $\boldsymbol{C}$. Quantification of outgrowth rates normalized to vehicle are shown in $\mathbf{D}$. Axon-specific knockdown of RhoA blocked CSPG-mediated inhibition of axonal growth. CSPG-mediated inhibition of axon growth was not affected by axon-specific transfection of control siRNA. Scale bar, $50 \mu \mathrm{m}$. E, CSPG-dependent growth inhibition is sensitive to RhoA levels. P6 DRG neurons were infected with lentivirus expressing EGFP-tagged RhoA or GST (control). GFP-positive axons were imaged at 0 and $3 \mathrm{~h}$ following CSPG treatment, with terminals indicated by white ( $0 \mathrm{~h}$ ) and black arrowheads ( 3 h). Compared with the control, overexpression (0.E.) of RhoA led to enhanced CSPG-dependent axon growth inhibition. Scale bar, $20 \mu \mathrm{m} .{ }^{*} p<0.05$, compared with control siRNA (A), or as indicated (D), ANOVA with Bonferroni posttest. Data are mean \pm SEM. A.U., Arbitrary units.

but not control siRNA, resulted in knockdown of RhoA mRNA and RhoA protein (decreased by $72.1 \%$ ) in axons without affecting RhoA mRNA in the contiguous cell bodies (Fig. $4 A, B)$. In axons lacking RhoA mRNA, the CSPG-induced decrease in axonal growth rate was markedly attenuated (Fig. $4 C, D)$, suggesting that local translation of RhoA in axons is required for CSPG-mediated axon outgrowth inhibition.

These data suggest that the magnitude of the growthinhibitory response of CSPG is linked to the levels of RhoA in axons. To confirm this idea, we monitored the effects of CSPG on axon growth following expression of either EGFP-tagged RhoA or GST (control). Axon outgrowth is 36.9\% slower with overexpression of RhoA than control after CSPG treatment (Fig. 4E). These data suggest that CSPG-dependent axon growth inhibition was significantly increased following expression of RhoA, indicating that the CSPG response is sensitive to the levels of RhoA.

\section{Discussion}

The signaling pathways that mediate the inhibitory effects of CSPGs on axon growth are poorly understood. Our data show that CSPGs can activate local translation in the growth cones of axons derived from postnatal sensory neurons, and that local translation promotes the effects of CSPGs on axon growth inhibition. Furthermore, we show that CSPGs induce local RhoA synthesis, and selective depletion of RhoA transcripts from axons markedly impairs the growth-inhibitory effects of CSPGs. These data identify CSPGs as novel regulators of local translation, and describe a novel mechanism by which RhoA is regulated in axons. It will be interesting to determine whether local translation of RhoA is used by other axonal growth inhibitory molecules such as Nogo, since a recent study showed that CSPG and Nogo both activate Nogo receptors (Dickendesher et al., 2012).

Although axon guidance cues, such as netrin-1, NGF, and Sema3A, induce the translation of specific axonal mRNAs (Piper 
and Holt, 2004), inhibitors of axonal regeneration have not been shown to regulate local translation. Each of these classes of signaling molecules modulate cytoskeletal dynamics in growth cones, which may explain the common use of local translation in these divergent signaling pathways. We observed that the increases in p4E-BP1 by CSPG can be seen after 5 min, suggesting that protein synthesis induced by CSPG is rapid in growth cones. A potential mechanistic link between CSPG signaling and local translation is suggested by the finding that CSPG binding to LAR alters Akt signaling (Fisher et al., 2011), which has been linked to local protein translation via mTOR (Klann and Dever, 2004).

In order for local translation to mediate the effects of CSPGs, ribosomes and mRNA must be present in axons. Although injured axons in adult animals are not thought to contain sufficient levels of ribosomes and mRNA for local translation (Piper and Holt, 2004), axons generated from axotomized DRG sensory ganglia in culture contain ribosomes and mRNA (Zheng et al., 2001). Injury of axons in vivo increases ribosome markers in distal axons (Verma et al., 2005). In addition to increased transport of ribosomes after injury, ribosomes may be transferred from myelinating cells into axons after injury (Court et al., 2008). The presence of ribosomes has also been reported in uninjured corticospinal tract axons (Walker et al., 2012). However, detecting mRNA in regenerating axons has been a challenge since the glial scar increases nonspecific binding of in situ probes, thus improved technology is needed to overcome this barrier. Recent studies show that intrathecal delivery of RhoA siRNA to the spinal cord after contusion injury leads to improvements in recovery including increased serotonergic fiber growth (Otsuka et al., 2011). It will be interesting to determine whether specific inhibition of axonal RhoA can be used to reduce axonal RhoA activity and promote regeneration.

\section{References}

Cohen MS, Bas Orth C, Kim HJ, Jeon NL, Jaffrey SR (2011) Neurotrophin-mediated dendrite-to-nucleus signaling revealed by microfluidic compartmentalization of dendrites. Proc Natl Acad Sci U S A 108:11246-11251. CrossRef Medline

Conrad S, Schluesener HJ, Trautmann K, Joannin N, Meyermann R, Schwab JM (2005) Prolonged lesional expression of RhoA and RhoB following spinal cord injury. J Comp Neurol 487:166-175. CrossRef Medline

Court FA, Hendriks WT, MacGillavry HD, Alvarez J, van Minnen J (2008) Schwann cell to axon transfer of ribosomes: toward a novel understanding of the role of glia in the nervous system. J Neurosci 28:11024-11029. CrossRef Medline

Cox LJ, Hengst U, Gurskaya NG, Lukyanov KA, Jaffrey SR (2008) Intraaxonal translation and retrograde trafficking of CREB promotes neuronal survival. Nat Cell Biol 10:149-159. CrossRef Medline

Dergham P, Ellezam B, Essagian C, Avedissian H, Lubell WD, McKerracher L (2002) Rho signaling pathway targeted to promote spinal cord repair. J Neurosci 22:6570-6577. Medline

Dickendesher TL, Baldwin KT, Mironova YA, Koriyama Y, Raiker SJ, Askew KL, Wood A, Geoffroy CG, Zheng B, Liepmann CD, Katagiri Y, Benowitz LI, Geller HM, Giger RJ (2012) NgR1 and NgR3 are receptors for chondroitin sulfate proteoglycans. Nat Neurosci 15:703-712. CrossRef Medline

Dou CL, Levine JM (1994) Inhibition of neurite growth by the NG2 chondroitin sulfate proteoglycan. J Neurosci 14:7616-7628. Medline

Dubreuil CI, Winton MJ, McKerracher L (2003) Rho activation patterns after spinal cord injury and the role of activated Rho in apoptosis in the central nervous system. J Cell Biol 162:233-243. CrossRef Medline

Eng H, Lund K, Campenot RB (1999) Synthesis of beta-tubulin, actin, and other proteins in axons of sympathetic neurons in compartmented cultures. J Neurosci 19:1-9. Medline

Fisher D, Xing B, Dill J, Li H, Hoang HH, Zhao Z, Yang XL, Bachoo R, Cannon S, Longo FM, Sheng M, Silver J, Li S (2011) Leukocyte common antigen-related phosphatase is a functional receptor for chondroitin sul- fate proteoglycan axon growth inhibitors. J Neurosci 31:14051-14066. CrossRef Medline

Fournier AE, Takizawa BT, Strittmatter SM (2003) Rho kinase inhibition enhances axonal regeneration in the injured CNS. J Neurosci 23:14161423. Medline

Fu Q, Hue J, Li S (2007) Nonsteroidal anti-inflammatory drugs promote axon regeneration via RhoA inhibition. J Neurosci 27:4154-4164. CrossRef Medline

Hengst U, Cox LJ, Macosko EZ, Jaffrey SR (2006) Functional and selective RNA interference in developing axons and growth cones. J Neurosci 26:5727-5732. CrossRef Medline

Hengst U, Deglincerti A, Kim HJ, Jeon NL, Jaffrey SR (2009) Axonal elongation triggered by stimulus-induced local translation of a polarity complex protein. Nat Cell Biol 11:1024-1030. CrossRef Medline

Jain A, Brady-Kalnay SM, Bellamkonda RV (2004) Modulation of Rho GTPase activity alleviates chondroitin sulfate proteoglycan-dependent inhibition of neurite extension. J Neurosci Res 77:299-307. CrossRef Medline

Klann E, Dever TE (2004) Biochemical mechanisms for translational regulation in synaptic plasticity. Nat Rev Neurosci 5:931-942. CrossRef Medline

Kurihara D, Yamashita T (2012) Chondroitin sulfate proteoglycans downregulate spine formation in cortical neurons by targeting tropomyosinrelated kinase B (TrkB) protein. J Biol Chem 287:13822-13828. CrossRef Medline

Ma TC, Campana A, Lange PS, Lee HH, Banerjee K, Bryson JB, Mahishi L, Alam S, Giger RJ, Barnes S, Morris SM Jr, Willis DE, Twiss JL, Filbin MT, Ratan RR (2010) A large-scale chemical screen for regulators of the arginase 1 promoter identifies the soy isoflavone daidzeinas a clinically approved small molecule that can promote neuronal protection or regeneration via a cAMP-independent pathway. J Neurosci 30:739-748. CrossRef Medline

Maekawa M, Ishizaki T, Boku S, Watanabe N, Fujita A, Iwamatsu A, Obinata T, Ohashi K, Mizuno K, Narumiya S (1999) Signaling from Rho to the actin cytoskeleton through protein kinases ROCK and LIM-kinase. Science 285:895-898. CrossRef Medline

Monnier PP, Sierra A, Schwab JM, Henke-Fahle S, Mueller BK (2003) The Rho/ROCK pathway mediates neurite growth-inhibitory activity associated with the chondroitin sulfate proteoglycans of the CNS glial scar. Mol Cell Neurosci 22:319-330. CrossRef Medline

Niederöst B, Oertle T, Fritsche J, McKinney RA, Bandtlow CE (2002) Nogo-A and myelin-associated glycoprotein mediate neurite growth inhibition by antagonistic regulation of RhoA and Racl. J Neurosci 22: 10368-10376. Medline

Otsuka S, Adamson C, Sankar V, Gibbs KM, Kane-Goldsmith N, Ayer J, Babiarz J, Kalinski H, Ashush H, Alpert E, Lahav R, Feinstein E, Grumet M (2011) Delayed intrathecal delivery of RhoA siRNA to the contused spinal cord inhibits allodynia, preserves white matter, and increases serotonergic fiber growth. J Neurotrauma 28:1063-1076. CrossRef Medline

Piper M, Holt C (2004) RNA translation in axons. Annu Rev Cell Dev Biol 20:505-523. CrossRef Medline

Richter JD, Sonenberg N (2005) Regulation of cap-dependent translation by eIF4E inhibitory proteins. Nature 433:477-480. CrossRef Medline

Rodriguez OC, Schaefer AW, Mandato CA, Forscher P, Bement WM, Waterman-Storer CM (2003) Conserved microtubule-actin interactions in cell movement and morphogenesis. Nat Cell Biol 5:599-609. CrossRef Medline

Shen Y, Tenney AP, Busch SA, Horn KP, Cuascut FX, Liu K, He Z, Silver J, Flanagan JG (2009) PTPsigma is a receptor for chondroitin sulfate proteoglycan, an inhibitor of neural regeneration. Science 326:592-596. CrossRef Medline

Silver J, Miller JH (2004) Regeneration beyond the glial scar. Nat Rev Neurosci 5:146-156. CrossRef Medline

Taylor AM, Blurton-Jones M, Rhee SW, Cribbs DH, Cotman CW, Jeon NL (2005) A microfluidic culture platform for CNS axonal injury, regeneration and transport. Nat Methods 2:599-605. CrossRef Medline

Verma P, Chierzi S, Codd AM, Campbell DS, Meyer RL, Holt CE, Fawcett JW (2005) Axonal protein synthesis and degradation are necessary for efficient growth cone regeneration. J Neurosci 25:331-342. CrossRef Medline

Walker BA, Hengst U, Kim HJ, Jeon NL, Schmidt EF, Heintz N, Milner TA, Jaffrey SR (2012) Reprogramming axonal behavior by axon-specific viral transduction. Gene Ther 19:947-955. CrossRef Medline 
Wight TN, Kinsella MG, Qwarnström EE (1992) The role of proteoglycans in cell adhesion, migration and proliferation. Curr Opin Cell Biol 4:793-801. CrossRef Medline

Wu KY, Hengst U, Cox LJ, Macosko EZ, Jeromin A, Urquhart ER, Jaffrey SR (2005) Local translation of RhoA regulates growth cone collapse. Nature 436:1020-1024. CrossRef Medline

Zheng JQ, Kelly TK, Chang B, Ryazantsev S, Rajasekaran AK, Martin KC, Twiss JL
(2001) A functional role for intra-axonal protein synthesis during axonal regeneration from adult sensory neurons. J Neurosci 21:9291-9303. Medline

Zivraj KH, Tung YC, Piper M, Gumy L, Fawcett JW, Yeo GS, Holt CE (2010) Subcellular profiling reveals distinct and developmentally regulated repertoire of growth cone mRNAs. J Neurosci 30:15464-15478. CrossRef Medline 